\title{
Socio demographic characterization of users of Child and Adolescent Psychosocial Care Centers in the state of São Paulo
}

\author{
Caracterização sociodemográfica de usuários de Centros de \\ Atenção Psicossocial Infanto-Juvenil do estado de São Paulo
}

\author{
Ana Cecília Andrade de Moraes WEINTRAUB \\ Michelle de Sousa VASCONCELLOS \\ Isabella Teixeira BASTOS \\ Felipe Lessa da FONSECA ${ }^{1}$ \\ Alberto Olavo Advíncula REIS
}

\begin{abstract}
The "Centros de Atenção Psicossocial Infanto-Juvenil" are dispositives of treatment for children and adolescents suffering from severe mental disorders. This article describes sociodemografic characteristics of users of those centers between September 2008 and February 2009 in the state of São Paulo, Brazil. Data from active files randomly selected was collected in 19 Centers in the state of São Paulo. The characteristics analyzed were divided in four groups of variables: identity; living conditions; family structure; schooling and occupation. The results indicated a higher concentration of users between 10 to 14 years-old; prevalence of males; tendency to nuclear and reduced family arrangements (45\%); care primarily given by the mother (57\%) and high frequency of users attending the regular school (86\%). It was possible to identify a well-defined socio demographic profile of users, with differences regarding gender, attending the regular school and/or other institutions, as well as sharing a nuclear family arrangement.
\end{abstract}

Uniterms: Adolescent; Children; Juvenile; Mental hearth services; Sociodemographic profile.

\section{Resumo}

Os Centros de Atenção Psicossocial Infanto-Juvenil são dispositivos de tratamento para transtornos mentais severos e persistentes em crianças e adolescentes. O artigo descreve características sociodemográficas de usuários destes centros, entre setembro de 2008 e fevereiro de 2009, no Estado de São Paulo. Foram coletados dados de prontuários ativos selecionados aleatoriamente em 19 Centros de Atenção Psicossocial Infanto-Juvenil do Estado. As características analisadas originaram-se de quatro grupos de variáveis: identificação, moradia, estrutura familiar e escolaridade e ocupação. Os resultados apontaram para uma maior concentração de usuários de 10 a 14 anos de idade; prevalência do sexo masculino; tendência para arranjos familiares nucleares (45\%), cuidado predominantemente materno (57\%) e grande frequência de usuários em escola regular (86\%). Foi identificado um perfil de usuário definido com diferenças de frequência relacionadas ao sexo, inserido na escola regular e/ou em outros tipos de instituições, bem como partilhando da convivência de uma família nuclear, especialmente contando com o cuidado materno.

Unitermos: Adolescentes; Crianças; Infantojuvenil; Serviços de saúde mental; Perfil sociodemográfico.

$\nabla \nabla \nabla \nabla$

1 Universidade de São Paulo, Faculdade de Saúde Pública, Laboratório de Saúde Mental Coletiva. Av. Dr. Arnaldo, 715, Pacaembú, 01246-904, São Paulo, SP, Brasil. Correspondência para/Correspondence to: A.C.A.M.WEINTRAUB. E-mail: <ana.cecilia.moraes@usp.br>.

Support: Fundação de Amparo à Pesquisa do Estado de São Paulo, Project no 2006/06902-2. 
Various studies indicate a high prevalence rates of mental disorders in the child and adolescent population (from 15.8\% to 50\%), similar to those seen in the adult population (Almeida Filho, 1982; Laurindsen $\&$ Tanaka, 2005). The wide variation in results is due mainly to the large methodological heterogeneity found in the different studies (Brasil, 2004; 2008). According to the World Health Organization (Organização Mundial da Saúde, 2002), the prevalence of mental disorders in childhood and youth is between $10 \%$ and $20 \%$ and the most common are the behavioral, attention, emotional and hyperactivity disorders. Relatively recently, in parallel to investigations on the prevalence of disorders, there has been the implementation of a new policy in mental health that includes child and adolescent health in its public and collective dimensions. The Centros de Atenção Psicossocial Infanto-Juvenil (CAPSi, Child and Adolescent Psychosocial Care Centers), created in 2002 and fundamental for the ongoing psychiatric reform in Brazil, are geared to meet the specific needs of children and adolescents when they have severe and/or persistent psychological distress (Hoffman, Santos \& Mota, 2008; Lancetti \& Amarante, 2008). In 2008 the state of São Paulo had 22 CAPSi.

The Centros de Atenção Psicossocial Infanto-juvenil are social facilities belonging to a field in which the paradigm implies constant readjustments and the creative search for solutions. Despite the official regulations, passed almost one decade after their creation, the CAPSi have possibly acquired particular and diverse features. Understanding the characteristics of the population attended by the CAPSi, beyond the epidemiologic interest (Pinto \&Vansan, 1994), becomes a way of comprehending their public identity. Public policies, planning, review of intervention strategies, organization of services, and allocation of resources, among other things, rely on knowledge of the characteristics of the users. However, there are very few studies that describe the general sociodemographic characteristics of this population. With the exception of the study by Hoffmann et al. (2008), other investigations that attempt to describe the characteristics of the users of CAPSi have either been restricted to one or a few care units, or the populations of specific municipalities or schools (Assis, Avanci \&
Oliveira, 2009; Delfini, Dombi-Barbosa, Fonseca, Tavares \& Reis 2009; Ferrioli, Marturano \& Puntel, 2007).

Couto, Duarte and Delgado (2008) analyzed publications and official data from the Brazilian government in 2000 regarding national public services related to children and adolescents. Crivelatti, Durman and Hofstatter (2006) carried out a qualitative study with six adolescents attending a CAPSi, investigating their feelings about depression and the knowledge they possessed about the disease, including sociodemographic data, such as gender, age, race, education, family income, time and type of treatment performed in the CAPSi. Delfini et al. (2009). correlated some sociodemographic data (gender, age group) with diagnoses of mental disorders in a CAPSi unit.

From a similar perspective to the work of Delfini et al. (2009) and Hoffmann et al. (2008), the present article reports the results of a study that aimed to present the general characteristics of the CAPSi users in a geopolitical and demographic region that concentrates one third of the social facilities focused on mental health care, the state of São Paulo. It is comprehended that this problem becomes even more crucial when considering that the care directed toward the child and adolescent population has always been left in a marginal position in relation to the adult problem. The present study not only fills this gap but also provides the descriptive basis from which the public policy makers, the CAPSi team and the managers can reference in order to strengthen and implement actions aimed at this population. It was therefore decided to focus this report on the sociodemographic characteristics of the CAPSi of the state of São Paulo, analyzed from the active patient records from September 2008 to February 2009.

\section{Method}

\section{Participants}

The representative sample for this descriptive study was composed of 921 patient records of children and adolescents, taking into account an expected 30\% loss. The sample size calculation was based on the prevalence of twenty-one mental health problems of children and adolescents in Brazil and was proportional 
to the total number of active patient records in the units studied $(2,216)$ with a significance level of $95 \%$ and an acceptable error of $3 \%$. The inclusion criteria for the study were: the active patient records of users enrolled in nineteen units CAPSi in the state of São Paulo registered in the Ministry of Health for at least three months prior to the date of collection.

\section{Instruments and Procedures}

The data were extracted from the sample of patient records from all the units in the state of São Paulo at the time of the study. Once the unit and number of patient records to be consulted had been identified, a standardized research protocol, previously formulated for the collection, was used. Some of the categories of this protocol were based on a set of variables inferred from models of public network patient records, particularly used in the CAPSi. The data were recorded in the study protocols by trained researchers and, after the collection, were coded and entered into the Epi Info 3 v5.1 Database Program. The statistical software Stata 10.1 was used for the statistical analysis. The data, organized and arranged in tables, were then subjected to simple descriptive statistical analysis.

Patient records are a rich and convenient source of information for obtaining data regarding the health situation and characteristics of the population. Despite the known gaps in their completion, patient records are a valuable work instrument for any healthcare professional and have strong implications in the management of the services. Several studies have used them as a source of research data (Pereira et al., 2008; Prado \& Fujimori, 2006; Reis et al., 2009). Conversely, as emphasized by Romero and Cunha (2006), the studies that use patient record data, such as this one, encounter a lack of data or gaps in the completion of the information as common obstacles. Thus, the limits of this study refer to the use of a particular and restricted source of information about the users, as it is not possible to define how much the written data correlate with the experience reported by the users and their caregivers. Furthermore, the patient records used as a data source for the study showed considerable differences in regularity and/or quality in the completion of the data in the different units. In the present study, when the proportion of missing data for a particular variable became significant, or omissions were above 50\%, the data were used only as an indicative element. This was the case for the categories "skin color", "housing situation", "responsible for the income" and "performing an occupational activity".

For the socio-demographic analysis of the reference population four groups of variables were retained that comprise the following categories:

1) Identification: age group, gender, skin color.

2) Housing: type of residence (house, apartment, shack, collective housing, shelter, or other), type of housing situation (rented, owned, borrowed, slum, or other).

3) Family structure: family composition (the relatedness between the inhabitants of the home of the user), who is responsible for the care of the user, who is responsible for the family income.

4) Education and occupation: institutions attended by the user, type of institution and type of management of the institution (public or private), calculation of school adequacy (age relative to school grade), performance of occupational activities, performance of paid occupational activities, government benefits received by the family.

The study was conducted according to the regulations governing research with humans contained in resolutions no 196/96 and n 251/97 of the National Council of the Health Ministry of Health of Brazil, and approved by the Research Ethics Committee of the Faculty of Public Health, Universidade de São Paulo, under the protocol no 1616, on April 20, 2007. All those responsible for the CAPSi units from which the patient records data were collected signed the Terms of Approval for the study.

\section{Results}

\section{Identification}

The age variable was divided into five age groups: from zero to 4 years; 5 to 9 years; 10 to 14 years; 15 to 19 years; and over 20 years of age. According to the sample data, the majority of the users were concentrated in the 10 to 14 years age group (40.2\%), followed by the 5 to 9 years (26.3\%) and the 15 to 19 
years $(24,3 \%)$ age groups. This variable, when considered together with the variable "gender" of the users, reveals significant data for the analysis of the CAPSi user population. These state facilities had 69.8\% of boys and $30.2 \%$ of girls in attendance. The distribution of the users corroborated previous studies by presenting the prevalence of the 10 to 14 years age group and boys receiving healthcare (Delfini et al., 2009, Golfeto \& Ribeiro, 1984; Hoffman et al., 2008; Ronchi \& Avellar, 2010; Santos, 2006; Sposito \& Savoia, 2006). Figure 1 presents the comparison between the total values of the age group and gender of the CAPSi users of the state of São Paulo studied. It is possible to note that up to the 10 to 14 years age group, the prevalence of boys who sought CAPSi was maintained, however, from the 15 to 19 years age group care for the female population prevailed.

As explained above, the percentage of missing data in the patient records regarding "skin color" prevented the analysis of this variable in this study.

\section{Housing}

In relation to the housing data, the volume of absence of notes in the patient records was $47.7 \%$ of the sample for"type of residence" and $67.3 \%$ for "housing situation". The findings are detailed in Table 1, taking into consideration that the "housing situation" data are purely indicative. It is worth noting that the majority of

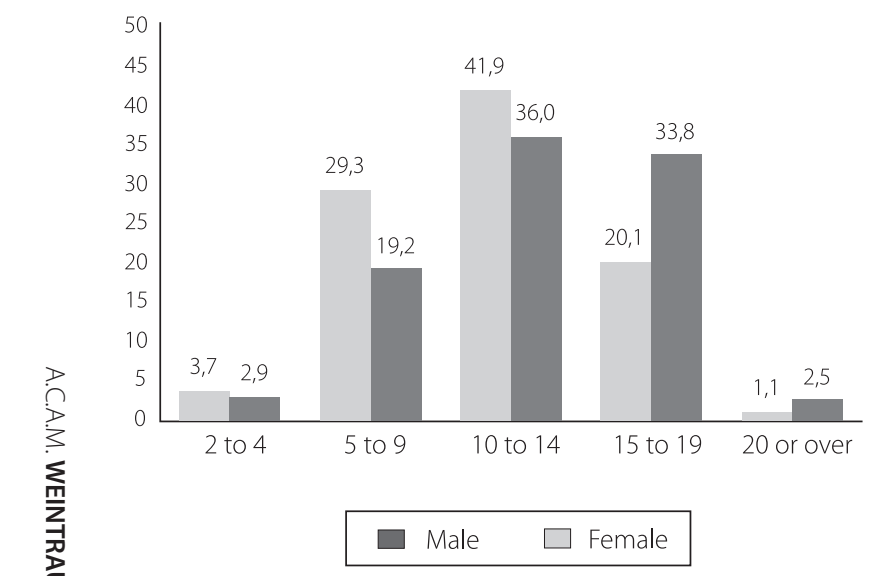

Figure 1. Age and gender distribution of the CAPSi users of the state of São Paulo, 2008/2009 ( $n=921$ ).

Source: Reis A.O.A. Sociodemographic and epidemiological characterization of the CAPSi users of the state of São Paulo. Fundação de Amparo à Pesquisa do Estado de São Paulo, Process n²006/06902-2. the patient records indicated that users inhabited houses or apartments and/or their own properties, which could indicate a relatively stable condition of life. This category also analyzed the situations in shelters, finding that 32 users, 3.5\% of the sample, lived in shelters. The data collected from the patient records also showed that this small group was concentrated in the 10 to 14 years age group, in which a large part of the population was concentrated.

\section{Family Structure}

The patient records indicated that the CAPSi users in the state had a tendency to form nuclear families, constituted by the couple and their children, as $45.0 \%$ of the notes indicated that the users lived with both parents. A household with only one of the parents, the father or mother, was reported by $28.7 \%$ of the users according to the patient records. Other studies with CAPSi users from 0 to 14 years of age also highlighted the tendency for families formed by the couple and their children (Golfeto \& Ribeiro, 1984; Pereira et al., 2008). Households with the mother, with or without other family members, composed $73.6 \%$ of the total. In the distribution analysis by age groups, $93.0 \%$ of the people aged 20 and over lived with their mother, with this value being $70.1 \%$ for the people in the 15 to 19 years age group. More detailed results regarding the family structure of users were found than those analyzed by Vasconcellos, Gribel and Moraes (2008), who said they was very little data related to the family situation in the patient records. In the present study, although it was not possible to specify characteristics such as age, education and occupation of the members of the users'family, data on co-habitation, as well as on the regulation and maintenance of the family living arrangements, revealed information about the context in which they were included.

Regarding the number of co-inhabitants, the majority lived with 4 people in the household (21.5\%), followed by 5 (15.6\%) and 3 people (14.2\%), according to the user. There were very few who lived with more than seven people in the house, not even corresponding to $7.0 \%$ of the total. Considering that the information regarding those responsible for the income are only indicative, due to having $58.3 \%$ of the data missing, it can be observed, from the data, that in $20.4 \%$ 
Table 1

Type of residence and housing situation of the CAPSi users of the state of São Paulo, 2008/2009

\begin{tabular}{|c|c|c|c|c|c|c|c|}
\hline \multirow{2}{*}{ Type of residence/Housing situation } & \multicolumn{2}{|c|}{ Male $(n=634)$} & \multicolumn{2}{|c|}{ Fermale $(n=275)$} & \multicolumn{2}{|c|}{ Total $(n=909)$} & \multirow{2}{*}{$p^{*}$} \\
\hline & $\mathrm{n}^{* *}$ & $\%^{* *}$ & $\mathrm{n}^{* *}$ & $\%^{* *}$ & $\mathrm{n}^{* *}$ & $\%^{* *}$ & \\
\hline Type of residence & & & & & & & 0.083 \\
\hline House/Apartament & 303 & 47.8 & 119 & 43.3 & 422 & 46.4 & \\
\hline Colletive housing & 8 & 1.3 & 6 & 2.2 & 14 & 1.5 & \\
\hline Shack & 4 & 0.6 & 0 & 0 & 4 & 0.4 & \\
\hline Shelter & 16 & 2.5 & 16 & 5.8 & 32 & 3.5 & \\
\hline Other & 2 & 0.3 & 1 & 0.4 & 3 & 0.3 & \\
\hline Ignored & 301 & 47.5 & 133 & 48.4 & 434 & 47.7 & \\
\hline Housing situation & & & & & & & 0.583 \\
\hline Own & 82 & 13.3 & 41 & 15.8 & 123 & 14.0 & \\
\hline Rent & 36 & 5.8 & 11 & 4.3 & 47 & 5.4 & \\
\hline Borrowed & 34 & 5.5 & 10 & 3.9 & 44 & 5.0 & \\
\hline Slum & 47 & 7.6 & 14 & 5.4 & 61 & 7.0 & \\
\hline Other & 10 & 1.6 & 2 & 0.8 & 12 & 1.4 & \\
\hline Ignored & 409 & 66.2 & 181 & 69.9 & 590 & 67.3 & \\
\hline
\end{tabular}

Note: *According to Pearson's Chi-square test or Fischer's when Pearson's was not appropriate; ${ }^{* *}$ Data regarding the presence of the variable in relation to their respective totals $(n)$.

of the cases the father was responsible, in 9.0\% the mother and in 3.4\% both the father and mother.

Considering those responsible for the care, the mother appeared as the primary caregiver in $57.0 \%$ of cases, the grandparents in $7.8 \%$, and the father in $2.5 \%$, followed by care in shelters in $2.1 \%$ of cases. Thus, the intersection between the data on those responsible for the income, even if only indicative, and those responsible for the care of the child, revealed that in $82.7 \%$ of the cases where the mother was responsible for the income, she was also responsible for the care of the child. It was the same situation the grandmother, as in $84.2 \%$ of cases in which she was responsible for the household income she was also responsible for the care of the user. However, the father, when responsible for the income, was not responsible for the care in $93.5 \%$ of the families of the service, delegating this responsibility to the mother in $82.2 \%$ of cases. The considerable presence of the mother in the quotidian of the CAPSi users surveyed was therefore observed, regarding both the family living arrangements, as well as the function of care.

\section{Education and occupation}

Data on occupation of the CAPSi users of the State, collected through the patient records, revealed that $80.0 \%$ attended an institution in addition to CAPSi, as shown in Table 2. Of these, $89.0 \%$ attended a regular school and $6.3 \%$ attended a special school. The regular public school (state or municipal) was attended by the majority of the users entered in the school system and among those who attended a special school, the majority were in the public school network.

It was possible to infer information from the patient records regarding the school adequacy of the children and adolescents attending the CAPSi of the state. It was necessary to make a correction of the information regarding "age" in the patient records as it was only recorded when the patient record was created. The data used were the year of birth of the user, according to the information in the patient record, the grade in which they were in the school and the year of the information regarding the grade. However, once again, when performing the calculation between the year of birth of the child, the grade in which they were studying that year and the year in which this data was provided, in $45.0 \%$ of the cases there was at least one piece of information missing, making it impossible to make more precise statements about the school adequacy. From the data found, it was observed that the greater dispersion between the grades was at 12 years of age, in which there were children in the first grade through to the eighth grade of elementary 
Table 2

Other institutions frequented by the CAPSi users of the state of São Paulo, 2008/2009

\begin{tabular}{|c|c|c|c|c|c|c|c|}
\hline \multirow{2}{*}{$\begin{array}{l}\text { Frequency of institutions/Which } \\
\text { institutions? }\end{array}$} & \multicolumn{2}{|c|}{ Male $(n=634)$} & \multicolumn{2}{|c|}{ Fermale $(n=275)$} & \multicolumn{2}{|c|}{ Total $(n=909)$} & \multirow{2}{*}{$p^{*}$} \\
\hline & $\mathrm{n}^{* *}$ & $\%^{* *}$ & $\mathrm{n}^{* *}$ & $\%^{* *}$ & $\mathrm{n}^{* *}$ & $\%^{* *}$ & \\
\hline Frequents other institutions? & & & & & & & 0.075 \\
\hline No & 43 & 6.8 & 31 & 11.3 & 74 & 8.1 & \\
\hline Yes & 515 & 81.2 & 212 & 77.1 & 727 & 80.0 & \\
\hline Ignored & 76 & 12.0 & 32 & 11.6 & 108 & 11.9 & \\
\hline Which institution? & & & & & & & 0.104 \\
\hline Shelter & 3 & 0.6 & 6 & 2.8 & 9 & 1.2 & \\
\hline Creche & 6 & 1.2 & 1 & 0.5 & 7 & 1.0 & \\
\hline Special school & 34 & 6.6 & 12 & 5.7 & 46 & 6.3 & \\
\hline Regular school & 460 & 89.3 & 186 & 87.7 & 646 & 88.9 & \\
\hline Fundação casa & 1 & 0.2 & 0 & 0 & 1 & 0.1 & \\
\hline Others & 8 & 1.6 & 4 & 1.8 & 12 & 1.6 & \\
\hline Ignored & 3 & 0.6 & 3 & 1.4 & 6 & 0.8 & \\
\hline
\end{tabular}

Note: *According to Pearson's Chi-square test or Fischer's when Pearson's was not appropriate; ${ }^{* *}$ Data regarding the presence of the variable in relation to their respective totals $(n)$.

Table 3

Extra activities and receiving benefits for the CAPSi users of the state of São Paulo, 2008/2009

\begin{tabular}{|c|c|c|c|c|c|c|c|}
\hline \multirow{2}{*}{ Extra activities/Benefits } & \multicolumn{2}{|c|}{ Male $(n=634)$} & \multicolumn{2}{|c|}{ Fermale $(n=275)$} & \multicolumn{2}{|c|}{ Total $(n=909)$} & \multirow{2}{*}{$p^{*}$} \\
\hline & $\mathrm{n}^{* *}$ & $\%^{* *}$ & $\mathrm{n}^{* *}$ & $\%^{* *}$ & $\mathrm{n}^{* *}$ & $\%^{* *}$ & \\
\hline Extra activity & & & & & & & 0.969 \\
\hline No & 206 & 32.5 & 91 & 33.1 & 297 & 32.7 & \\
\hline Yes & 77 & 12.2 & 32 & 11.6 & 109 & 12.0 & \\
\hline Ignored & 351 & 55.4 & 152 & 55.3 & 503 & 55.3 & \\
\hline Paid activity & & & & & & & 0.759 \\
\hline No & 32 & 41.6 & 11 & 34.4 & 43 & 39.5 & \\
\hline Yes & 12 & 15.6 & 5 & 15.6 & 17 & 15.6 & \\
\hline Ignored & 33 & 42.9 & 16 & 50.0 & 49 & 45.0 & \\
\hline Benefits & & & & & & & 0.487 \\
\hline No & 427 & 67.4 & 174 & 63.3 & 601 & 66.1 & \\
\hline Yes & 138 & 21.8 & 68 & 24.7 & 206 & 22.7 & \\
\hline Ignored & 69 & 10.9 & 33 & 12.0 & 102 & 11.2 & \\
\hline
\end{tabular}

Note: ${ }^{*}$ According to Pearson's Chi-square test or Fischer's when Pearson's was not appropriate; ${ }^{* *}$ Data regarding the presence of the variable in relation to their respective totals $(n)$.

education - equivalent to 8 years of dispersion considering the system of 8 years of study. At the ages 11 years, 13 years, 14 years and 16 years seven different school years were found for each age, configuring them as the ages with the second largest dispersion among the grades.

It is important to remember that the state of São Paulo had, at the time of the study, the continued progression system (São Paulo, 1997) that promotes the

388 completion of the elementary education years by 14 or 15 years of age. By using this approach for the data of this study, it was observed that $67.7 \%$ of the young people aged 15 years were attending the $8^{\text {th }}$ grade of elementary education or the $1^{\text {st }}$ year of high school education. However, there was a wide dispersion in relation to the school years for the various ages and data was found regarding very advanced users in relation to their age. In the study by Ronchi and Avellar (2010), it was possible to identify that eighty percent of 
the CAPSi child and adolescent patients studied were mostly distributed in the initial stages of elementary education. These figures approach those found by Santos (2006), however, differ from the profile of users investigated in this study.

Finally, the information regarding the "occupational activities" performed by the users also did not appear in most of the patient records. From the indicative data existing in these documents, $12.0 \%$ of the CAPSi users of the state performed some type of occupational activity, and of these, $15.6 \%$ received payment for what they did, covering the age groups between 10 and 20 years, as shown in Table 3. It was not possible to define the type of work performed from the patient records. In addition to this information, it was observed that $22.7 \%$ received some benefits from the government, however, these varied widely, from free transportation, family support and school support to exemption from payment of electricity.

\section{Discussion}

Studies that investigate the scenario of child and adolescent mental health care provide subsidies for the implementation of practices and decisions with respect to specific care for this population. Few studies were found in Brazil that present the sociodemographic data of the users of child and adolescent mental health of the public network (Hoffman et al., 2008), as studies and services in the mental health public network are mostly aimed at the adult population.

The present study included sociodemographic data that allow the delineation of the child and adolescent population and their family contexts, inserted in the psychosocial care services. A higher frequency of users in the 10 to 14 years age group was obtained, a range in which it is possible to note the passage from the prevalence of male users to the prevalence of female users, due to the termination in the use of the service by the male population.

Given the above, it is worth questioning whether the prevalence of mental disorders according to gender is responsible for the unequal sexual composition of the CAPSi users, or whether there are other reasons for this. It should be noted that characteristics of the psychosocial development of the male and female children and adolescents, taking into consideration their different stages, contribute to or influence the unequal manifestation of mental disorders according to gender and that there are social configurations that lead to boys being more often taken as having severe mental disorders. Conversely, the relative decrease in the adolescent male population in the composition of the CAPSi user population in the higher age groups is explained by the classic male abandonment of healthcare. Associated with the male representation of omnipotence, this behavior of abandonment of the services by men is present and fairly widespread in the concept that public primary healthcare services are intended almost exclusively for women, children and the elderly (Figueiredo, 2005). The withdrawal of a portion of the male adolescents from these places identified with the feminine and with childhood is understandable from the point of view of the attributes assigned to the gender. However, the imaginary effects that lead to the withdrawal from the CAPSi cannot always be attributed to the isolated figure of the adolescent. Eventually, the family, the social group and even the characteristics of the service network operate in order to push them away or to undermine their adherence to the service.

It is also worth considering efforts made by some studies to investigate possible indicators of developmental problems or mental health problems in children. Kupfer et al. (2010) sought to analyze the predictive value of an instrument created by them to measure risks throughout the development and psychic constitution of children, and Assis, Pires, Pesce, Avanci and Oliveira (2011) examined psychosocial risk factors related to socioeconomic development. Both studies did not focus their analysis on gender differences, however, highlighted several factors that may contribute or hinder the development of children and adolescents.

In the present study, the family composition was seen to be predominantly nuclear, consisting of the mother, father and children, in which the mother plays the role of caregiver and is the more constant presence within the families. It was also possible to observe that most users lived under conditions which can be described as stable and they co-habited with a small 
number of people. It is possible to question the way in which the family organization affects the mental health of children and adolescents, considering the quality of the bond of care and attention with the caregivers and the economic conditions of the family. Pires, Silva and Assis (2012) point out in their study that the existence of family dysfunction may be related to the prevalence of attention deficit disorder and hyperactivity. Considering the issue of education, the CAPSi users were mostly students of regular public schools, who did not perform occupational activities outside of the school. It may be questioned whether, in view of the CAPSi policy of promoting social inclusion and intersectionality, the school would be the main link to the healthcare service. The analysis of the demographic data showed that the school is indeed very present in the lives of users, according to the patient records, either as point of connection and work with the network or as a depository for their problems.

As human beings fall under the various cultural norms of society due to certain characteristic processes, it can be asked what symbolic conditions are needed for the process of socialization of the child whose primary locus is the school? It can also be asked whether the school can be associated with the higher sensitivity to mental disorders of the male child and adolescent population, considering that in the school there may be a greater perception of behavioral components, which are probably less tolerated, such as agitation, aggression, and poor school performance, habitually linked to the social representation that are made about the boy. For the female infant universe the suffering might be confused with cultural characteristics related to gender, such as passivity, docility and melancholy. Within this perspective the problems that affect the mental health of girls only acquire greater social visibility as they enter puberty, with a transformation of their social role from child to adolescent and their greater social inclusion. It is understood that studies such as this one assist in the comprehension of how child and adolescent mental health has been accepted in Brazil and that, complemented with epidemiological studies and studies of the evaluation of the operation of the services, they can provide a basis for the development of new care strategies.

\section{References}

Almeida Filho, N. (1982). Estudos de prevalência de desordens mentais na infância em uma zona urbana de Salvador. Jornal Brasileiro de Psiquiatria, 31(4), 225-236.

Assis, S. G., Avanci J. Q., \&Oliveira R. V. C. (2009). Desigualdades sócio-econômicas e saúde mental infantil. Revista de Saúde Pública, 43(1), 92-100.

Assis, S. G., Pires, T., Pesce, R. P., Avanci, J. Q., \& Oliveira, R. V. C. (2011). Socioeconomic development, family income, and psychosocial risk factors: A study of families with children in public elementary schools. Cadernos de Saúde Pública, 27(2), S209-S221.

Brasil. Ministério da Saúde. (2004). Saúde mental no SUS: os centros de atenção psicossocial. Brasília: MS.

Brasil. Ministério da Saúde. (2008). Números de centros de atenção psicossocial por tipo e UF e indicador CAPS/100.000 habitantes. Brasília: MS.

Couto, M. C. V., Duarte, C. S., \& Delgado, P. G. G. (2008). A saúde mental infantil na saúde pública brasileira: situação atual e desafios. Revista Brasileira de Psiquiatria, 30(4), 384-389.

Crivelatti, M. M. B., Durman, S., \& Hofstatter, L. M. (2006). Sofrimento psíquico na adolescência. Texto e Contexto: Enfermagem, 15(Esp.), 64-70.

Delfini, P. S. S., Dombi-Barbosa, C., Fonseca, F. L., Tavares, C. M., \& Reis, A. O. A. (2009). Perfil dos usuários de um centro de atenção psicossocial infanto-juvenil da grande São Paulo, Brasil. Revista Brasileira de Crescimento e Desenvolvimento Humano, 19(2), 226-236.

Ferriolli, S. H. T., Marturano E. M., \& Puntel, L. P. (2007). Contexto familiar e problemas de saúde mental infantil no Programa Saúde da Família. Revista de Saúde Pública, 41(2), 251-259.

Figueiredo, W. (2005). Assistência à saúde dos homens: um desafio para os serviços de atenção primária. Ciência e Saúde Coletiva, 10(1), 105-109.

Golfeto, J. H., \& Ribeiro, M. V. M. (1984). Epidemiologia em psiquiatria infantil: um estudo de 295 casos. Neurobiologia, 47(2), 71-90.

Hoffmann, M. C. C. L., Santos, D. N., \& Mota, E. L. A. (2008). Caracterização dos usuários e dos serviços prestados por Centros de Atenção Psicossocial Infanto-Juvenil. Cadernos de Saúde Pública, 24(3), 633-642.

Kupfer, M. C. M., Jerusalinsky, A. N., Bernardino, L. M. F., Wanderley, D., Rocha, P. S. B., Molina, S. E., et al. (2010). Predictive values of clinical risk indicators in child development: final results of a study based on psychoanalytic theory. Revista Latinoamericana de Psicopatologia Fundamental, 13(1), 31-52.

Lancetti, A., \& Amarante, P. (2008). Saúde mental e saúde coletiva. In G. W. S. Campos, M. C. S. Minayo, M. D. Akerman, M. Drumond Jr \& Y. M. Carvalho (Orgs), Tratado de saúde coletiva (2a ed., p.615-634). São Paulo: Hucitec.

Lauridsen, E. P. P., \&Tanaka, O. Y. (2005). Problemas de saúde mental das crianças: abordagens na atenção básica. São Paulo: Annablume. 
Organização Mundial da Saúde. (2002). Relatório mundial da saúde 2001: saúde mental: nova concepção, nova esperança. Lisboa: OMS.

Pereira, A. T. S., Noronha, J., Cordeiro, H., Dain, S., Pereira, T. R., \& Cunha, F.T.S. (2008). O uso do prontuário familiar como indicador de qualidade da atenção nas unidades básicas de saúde. Cadernos de Saúde Pública, 24(1),123-133.

Pinto, R. C. M., \& Vansan, G. A. (1994). Aspectos epidemiológicos em psiquiatria infanto-juvenil. Neurobiologia, 57(2), 53-62.

Pires, T. O., Silva, C. M. F. P., \& Assis, S. G. (2012). Ambiente familiar e transtorno de défict de atenção e hiperatividade. Revista de Saúde Pública, 46(4), 624-632. Recuperado em julho 31, 2012, disponível em <www.scielo.br>.

Prado, S. R. L. A., \& Fujimori, E. (2006). Registro em prontuário de crianças e a prática da integralidade. Revista Brasileira de Enfermagem, 59(1), 67-71.

Reis, A. O., Dombi-Barbosa, C., Bertolino Neto, M. M. B., Prates, M. M. L., Delfini, P. S. S., \& Fonseca, F. L. (2009). Prontuários, para que servem? Representação dos coordenadores de equipe dos CAPSi a respeito do valor e da utilidade dos prontuários. Revista Brasileira de Crescimento e Desenvolvimento Humano, 19(3), 383-392.

Romero, D., \& Cunha, C. B. (2006). Avaliação da qualidade das variáveis sócio-econômicas e demográficas dos óbitos de crianças menores de um ano registrados no sistema de informações sobre mortalidade do Brasil (1996/2001). Cadernos de Saúde Pública, 22(3), 673-684.

Ronchi, J. P., \& Avellar, L. Z. (2010). Saúde mental da criança e do adolescente: a experiência do CAPSi da cidade de Vitória. Psicologia: Teoria e Prática, 12(1),71-84.

São Paulo. (1997, 5 agosto). Deliberação CEE 09/97, de 30 de julho de 1997. Institui, no sistema de ensino do Estado de São Paulo, o regime de progressão continuada no ensino fundamental. Diário Oficial do Estado, 12-13.

Santos, P. L. (2006). Problemas de saúde mental de crianças e adolescentes atendidos em um serviço público de psicologia infantil. Psicologia em Estudo, 11 (2), 315-321.

Sposito, B. P., \& Savoia, M. G. (2006). Atendimento especializado a adolescentes portadores de transtornos psiquiátricos: um estudo descritivo. Psicologia: Teoria e Prática, 8(1), 31-47.

Vasconcellos, M. M., Gribel, E. B., \& Moraes, I. H. S. (2008). Registros em saúde: avaliação da qualidade do prontuário do paciente na atenção básica, Rio de Janeiro, Brasil. Cadernos de Saúde Pública, 24(1), 173-182.

Received on: 27/7/2011

Final version on: 10/8/2012

Approved on: 16/10/2012 